\title{
EL FOLKLORE Y SUS PARADOJAS
}

\author{
Honorio M. Velasco Maillo
}

Universidad Nacional de Educación a Distancia

RESUMEN. Uno de los rasgos más sobresalientes de la historia del Folklore en España y otras naciones europeas son sus paradojas. Propuesto primero como ciencia ha llegado a ser claramente rechazado por posteriores ambientes científicos. Tendría interés hacer una historia social del Folklore. Este artículo sugiere que tales paradojas y contradicciones están relacionadas con el paradigma científico que asumieron sus promotores, el Evolucionismo cultural y con un concepto idealizado de "pueblo", que ayudaron a construir presentando colecciones de materiales. También analiza las diferentes funciones sociales que ha cumplido el discurso folklórico.

La historia del Folklore en España - y en otras naciones europeasestá tan llena de paradojas que ése podría ser el rasgo que principalmente habría que destacar en ella. Si como primera propuesta el Folklore pretendía lograr el reconocimiento de ciencia, no puede dejar de reconocerse que la mayoría de los científicos hoy utilizan el término "folklore" para designar precisamente lo que consideran más alejado de la ciencia. Se usa como término despreciativo y denigratorio. Si tanto en sus primeros planteamientos como en posteriores esfuerzos se buscó para el Folklore su integración en la docencia universitaria, no puede dejar de reconocerse hoy que, lejos de estar incluido en los planes de estudio - con la notable excepción de los Conservatorios de Música-, se cultiva en escuelas, agrupaciones y sociedades como ocupación del tiempo de ocio. $\mathrm{Y}$ aquellos que pudieran conside- 
rarse profesionales del Folklore no son precisamente profesores universitarios, sino que ejercen sus no menos respetables saberes en el mundo del espectáculo. La historia del Folklore tiene mucho más atractivo como historia social que como historia de la ciencia'.

Hay tanta distancia entre las Sociedades de Folklore que Antonio Machado creó a fines de siglo pasado y las agrupaciones de Folklore que hoy aún proliferan en muchas ciudades españolas que como proceso evolutivo de un fenómeno social es difícil encontrar otro tan enigmático y sorprendente. Las Sociedades de Folklore como el Folkiore Andaluz, el Folklore Castellano, etc., es decir, según el plan de Machado, una al menos por cada región española, estaban integradas por gentes pertenecientes a la élite intelectual de la época. La Castellana, por ejemplo, tenía entre sus miembros a Francisco Giner, Joaquín Costa, Gumersindo de Azcárate y otros, vinculados a la Institución Libre de Enseñanza, y también a Núñez de Arce, Cossío, Laguna, Federico Rubio, etc. Krausistas, positivistas, darwinistas, spencerianos, etc., se adhirieron pronto a la empresa del Folklore con evidente ánimo científico y patriótico ${ }^{2}$. Machado presentó, primero en Sevilla, pero sobre todo en Madrid, el Folklore como un "saber" ${ }^{3}$. Puede parecer hoy curioso que aquellos intelectuales dividieran el Folklore en tantas ramas como ciencias. De modo que al constituir la Sociedad cada uno se encargó de su parcela: folklore literario, folklore jurídico, folklore de bellas artes, folklore botánico, folklore matemático, folklore pedagógi$\mathrm{co}$, folklore físico-químico, folklore geográfico y folklore médico 4 . Algunas de estas etiquetas suenan hoy estridentes, pero entonces estuvieron avaladas por gentes de enorme prestigio. El término Folklore designaba una

1 La primera e indispensable Historia del Floklore en España es: A. Guichot Y SiERrA, Noticia bistórica del Folklore, Sevilla, Hijos de Guillermo Alvarez, 1922; reimp. Sevilla, Junta de Andalucía, 1984. Tiene interés consultar algunos capítulos de L. y N. DE Hoyos, Manual de Folklore, Madrid, Revista de Occidente, 1947. Y, ya recientemente, J. PÉrez VIDAL, Los estudios de Folklore canario, Las Palmas, Mancomunidad de Cabildos, 1982; LI. PRAT, D. Llopart y J. PraT, La cultura popular a Catalunya, Barcelona, Serveis de Cultura Popular, 1982; J. L. PÉrez DE CASTRo, Introducción al Folklore de Asturias, Gijón, Ayalga, 1983. Igualmente, la obra de C. Ortiz sobre Luis de Hoyos (Madrid, CSIC, 1988) y los trabajos de C. ESTEVA, "Antropología, Folklore e identidad cultural", en VV.AA., Antropologia Cultural en Extremadura, Mérida, Asamblea de Extremadura, 1989, pp. 15-33, y L. DíAz, "Identidad y manipulación de la Cultura popular. Algunas anotaciones sobre el caso castellanom, en L. Díaz (coord.), Aproximación antropológica a Castilla y León, Barcelona, Anthropos, 1988, pp. 13-27. Pero falta un estudio del Folklore en España en el que se aborden las interesantes y complejas formas de cómo el Folklore ha penetrado en la vida social.

2 La composición de la Junta provisional de El Folklore Castellano aparece publicada en $E l$ Globo, el viernes 30 de noviembre de 1883.

3 Véase la Introducción a El Folk-lore Andaluz (1882), reimp. en Madrid, Ayuntamiento de Sevilla y Ed. Tres, Catorce, Diecisiete, 1981. Y, también, "El Folk-lore Español", en el tomo V de la Biblioteca de las tradiciones populares españolas, Sevilla, A. Guichot y Cía., 1884.

4 En la noticia de constitución de El Folk-lore Castellano antes aludida aparece así dividido. En parte, la división correspondía a las especialidades de los integrantes, como si cada uno hubiera aceptado que el Folk-lore era la ctapa previa a la formación de su ciencia. 
ciencia dedicada al conocimiento, al saber de los saberes del pueblo. Pero con el tiempo este término ha sufrido algunos leves desplazamientos semánticos. Se ha ido cargando de ambigüedad y hoy Folklore designa a la vez la ciencia y su objeto, es decir, el saber del pueblo y el saber, la ciencia que lo estudia. Este sintomático desplazamiento semántico tiene evidentemente que ver con la composición y actividades de las actuales sociedades y agrupaciones de Folklore, integradas generalmente por gentes tan entusiastas como aquéllos, aunque posiblemente no tan egregios, especializados en otras parcelas, a saber: canción, danza, instrumentos musicales y artesanía. Y los esforzados intentos por mantener el Folklore dentro del ámbito de la Ciencia han tenido que ampararse en otras denominaciones, y especialmente bajo la Etnología y la Etnografía, o bien le han reformulado como "Arte verbal" (etiqueta propuesta por W. Bascom) o "Cultura expresiva" (J. W. Fernández $)^{5}$.

En esencia, la historia del Folklore es, por un lado, una historia marcada por la popularización, pues pasó de ser una dedicación de una élite intelectual a ser una actividad de entusiastas amantes de las tradiciones que parece no requerir ninguna especial formación. Y, por otro lado, está marcada por la disociación entre el doble componente de Arte y de Ciencia que parece conllevar, de modo que por él se afanan tanto quienes tienen habilidades específicas para interpretarle, para reproducirle (es decir, lo que el término inglés perfomance indica), como quienes recopilan sus materiales y los estudian, es decir, tanto folklóricos como folkloristas. Unos y otros, aún hoy, como en los tiempos en los que se gestó, están animados por el noble objetivo de la revitalización, que en unos casos significa el mantenimiento de las tradiciones populares y en otros su recuperación. Pues el Folklore tiene mucho $-\mathrm{y}$ esto no debe olvidarse- de movimiento social de revitalización, de revival ${ }^{6}$.

Como primera propuesta a la hora de tratar no ya de resolver, sino simplemente de intentar comprender la paradójica historia del Folklore habría que subrayar este carácter que Caro Baroja y otros autores ${ }^{7}$ han

$5 \mathrm{~J}$. W. FERNÁNDEZ, "The mission of metaphor in expressive culture", Current Antbropology, 15 (1974), pp. 119-145; R. BAUMAN, "Verbal art as performance", American Antbropologist, 77 (1975), pp. 290-311.

6 En la consideración del Folklore como un movimiento de revitalización tendría que tenerse en cuenta las distintas épocas en las que parece haberse prestado un especial interés hacia aspectos de la vida "tradicional". Es claro que el Folklore estuvo en el núcleo de posiciones como la de Joaquín Costa y en la Renaixença catalana. Ya en los años veinte, la Exposición del traje español fue otro importante acontecimiento que daría lugar a la formación del Museo del Pueblo Español. Y, posteriormente, en los años sesenta, el auge de la canción folk y, más recientemente, la recuperación de determinadas formas festivas son otros tantos momentos de impulsos revitalizadores de distintos aspectos del Folklore. Puede decirse que el Folklore desde su gestación ha mantenido una cierta continuidad, pero cada uno de estos momentos o etapas revela diferentes modos y sentidos de la revitalización.

7 J. Caro Baroja, Lo que sabemos del Folklore, Madrid, Gregorio del Toro, 1967. También C. Esteva, o. c., alude a ello. 
destacado en su contexto de formación y que ha venido siendo una constante. La atención hacia lo popular, hacia lo rural, por parte de las élites no es en absoluto un rasgo exclusivo del siglo XIX. En el XIX, sin embargo, esta atención hacia lo popular la protagoniza un nuevo sector social que podría reconocerse como burguesía en un entorno político focalizado hacia la idea de nación. La burguesía, y más en concreto, grupos de intelectuales burgueses de mediados de siglo, habían percibido el resquebrajamiento de la sociedad tradicional. Estuvieron sometidos de un modo especial a la tensión entre las consecuencias de haber asumido la idea de Progreso y las nuevas reglas de vida impuestas por un nuevo orden económico y social generado con la Revolución Industrial y la inundación de la vida cotidiana por parte de los adelantos técnicos, particularmente en las ciudades, por un lado, y, por otro, la nostalgia provocada por el desarraigo que caracterizaba al movimiento romántico. La tensión no es en modo alguno ficticia y remite al estado de contradicción que parece caracterizar a las etapas de un cambio social. La revolución industrial llevó consigo una movilización de población del campo a la ciudad; la burguesía, sin embargo, comenzó a redescubrir el campo como lugar idílico. La idea de Progreso implicaba el abandono, cuando no la supresión, de modos y estilos de vida tradicionales; grupos de la burguesía, sin embargo, creían vivir una situación de desarraigo ante la endeble y artificial imagen de realidad que proporcionaba la Modernidad. El Folklore fue un movimiento gestado desde la Modernidad. Nació institucionalizándose en forma de Sociedades (o incluso de Academias, como proponía Sbarbi) y siguiendo pautas marcadas desde el exterior. Machado descubrió leyendo la Revue Celtique que el grupo vinculado a Federico de Castro en Sevilla y que publicaba cuentos, coplas y cantes flamencos en la Enciclopedia (no se puede pedir nombre más moderno) estaba haciendo Folklore sin saberlo ${ }^{8}$ Sin embargo, este descubrimiento es banal cuando se sitúa en su verdadera dimensión. Quienes realmente descubrieron que estaban haciendo Folklore, o más bien que tenían Folklore sin saberlo, fueron los informantes de Machado, las amas de cría y las criadas que su madre y él mismo contrataban para la casa y que provenían de zonas rurales"; los cantaores ocasionales en las tabernas sevillanas, muchos de ellos provenientes de sectores marginales; los viejos campesinos que entretenían sus ya indefinidos ratos de ocio en relatar a vera-

8 A. GUichot y SierRA, o. c., p. 163.

9 La primera de las colecciones de MACHADO, Colección de enigmas y adivinanzas en forma de diccionario, Sevilla, Imp. de R. Baldaraque, 1880, contiene numerosas adivinanzas de Talavera la Real y Llerena, pueblos de la provincia de Badajoz donde su madre, Cipriana Alvarez, pasó alguna temporada al lado de su hermana. Las gentes del barrio de Ollerías y de las huertas, según cuenta el propio Machado, la llamaban "la señora", y se acercaban a ella para contarle "cuanto sabían". Biblioteca de Tradiciones Populares, tomo VI, 1884, pp. 273-274. Una vez trasladado a Madrid, Machado publicó una serie de artículos sobre "El Folklore de Avila" en El Progreso. El primero de ellos comienza así: "Nueva criada en casa, nueva mina de Folklore..." 
neantes de fuera o señoritos de dentro cuentos antiguos; las gentes de los pueblos que celebraban sus fiestas de verano... (lo mismo que los que desempeñaban determinados oficios manuales, a medida que fueron residuales, descubrieron que hacían Artesanía sin saberlo $)^{10}$. El Folklore fue en cierta medida un invento de la Modernidad. Tal vez no baste aludir a la continuidad del movimiento romántico para explicar por qué las élites burguesas de la Modernidad se encontraron en situación de desarraigo.

La tensión se tornó paradoja y se instaló en el seno del Folklore desde el mismo momento en que sus iniciadores se adhirieron al paradigma teórico que entonces recorría Europa, el Evolucionismo, y en particular la versión spenceriana de él. En las bases de constitución de las Sociedades de Folklore redactadas por el grupo sevillano y adoptadas por el resto constaba que tales Sociedades tenían por objeto: "recoger, acopiar y publicar todos los conocimientos de nuestro pueblo en las más diversas ramas de la ciencia...". Se enumera a continuación todo un conjunto de materiales como refranes, cantares, cuentos, leyendas, costumbres, fiestas, etc., que deberían ser objeto de recopilación, y se termina con el siguiente párrafo: "y en suma, todos los elementos constitutivos del genio, del saber y del idioma patrios, contenidos en la tradición oral y en los monumentos escritos, como materiales indispensables para el conocimiento y reconstrucción científica de la historia y la cultura españolas" ${ }^{11}$.

En otro lugar he desglosado con minuciosidad estas bases, este concepto del Folklore ${ }^{12}$. Ahora me interesa subrayar cómo pensaban realizar esa "reconstrucción científica de la historia y la cultura española". Es sabido que Machado acometió la traducción de Primitive Culture, de E. Tylor, publicado once años antes de la constitución de la primera Sociedad de Folklore en España. Pero es en la Introducción a El Folklore Andaluz, la revista órgano de la Sociedad de Folklore, donde la teoría evolucionista es invocada para fundamentar el carácter científico del Folklore. Sus plantemientos son claros:

1. Analogía entre la evolución biológica y la evolución cultural.

2. En el saber popular se encuentran los verdaderos fósiles del pensamiento humano y los gérmenes imaginativos primeros de las ciencias y las artes modernas.

10 Sobre el cambio semántico de los términos "artesanía", "artesano" y términos afines puede verse H. Velasco, La artesanía en Extremadura. Una aproximación a los bombres, los trabajos y los objetos, Madrid, Ministerio de Industria y Energía, 1986.

11 "El Folk-lore español. Sociedad para la recopilación y estudio del saber y de las tradiciones populares. Bases", en El Folk-lore Andaluz, Sevilla, 1883, pp. 501-503.

12 H. Velasco, "El Evolucionismo y la evolución del Folklore», El Folk-lore Andaluz, 2. época, núm. 2, pp. 13-32. 
3. El Folklore está llamado a ser un poderoso auxiliar de la Antropo$\log ^{1}{ }^{13}$.

El paradigma científico que el Folklore adoptó le llevó a considerar el «saber popular» como digno de ser recuperado para poder reconstruir las etapas de una evolución que ellos mismos estaban experimentando. En el Folklore se hallaban "supervivencias", un concepto forjado por Tylor y en el que se basaba la posibilidad metodológica de delinear la evolución. Gracias a las "supervivencias", del mismo modo que gracias a los fósiles, era posible mostrar las secuencias evolutivas, en un caso, de la vida de la tierra; en este caso, de las culturas. Una "supervivencia" y, si se quiere, una fórmula extrema de ésta, una "superstición", era una especie de idea fosilizada, atribuible a las gentes de etapas anteriores, y mantenida, conservada precisamente por quienes no se habían incorporado al Progreso, sino que seguían rigiéndose por la tradición. Así, una "supervivencia", y aún más una "superstición", era un concepto forjado desde y por quienes practicaban la Ciencia, por quienes estaban en la órbita del Progreso, por quienes dejaron de ser hace tiempo sociedad rural y habían sido educados en la Civilización, es decir, en el saber y el modo de vivir de las ciudades. Las "supervivencias" se encontraban, pues, por el contrario, en las clases incultas y populares.

Lo singular, lo paradójico, era que aquellos que se identificaban como progresistas y liberales, que habían asumido las ideas científicas de la Modernidad, y entre ellas el Evolucionismo, precisamente en contra de posiciones oscurantistas y tradicionalistas, estaban prestando atención y recuperando ideas, creencias, costumbres, ritos y prácticas de vida tradicionales, que habían sido abandonadas o era necesario abandonar para poder preconizar una sociedad evolucionada, para poder desarrollar la Ciencia. Naturalmente, proponían sólo una recuperación intelectual. Sus fines eran exclusivamente científicos, disociando su actividad intelectual de sus asunciones personales y vitales. Se trataba de "reconstruir la historia y la cultura", no de retornar socialmente al pasado. Pero en la comunidad científica más preocupada por el futuro, por las innovaciones, parece haber quedado cristalizado un gesto de incomprensión, de duda ante el valor de recopilar todo ese conjunto de material fosilizado. Pues, como un académico de entonces criticaba: "¿Qué mérito ni qué poesía puede haber en un pregón de rositas encarnás?" ${ }^{14}$. Precisamente, equienes se adherían a los ideales científicos habrían de prestar mayor atención a viejas y caducas costumbres que a las importantísimas cuestiones que los nuevos tiempos estaban planteando?

Otro aspecto de la paradoja estaba en que el paradigma explicativo

13 La Introducción a El Folk-lore Andaluz es toda una confesión de fe evolucionista (l. c., pp. 1-10).

14 Véase A. Guichot, o. c., p. 22. 
evolucionista extendido al campo de las ideas implicaba que era el pueblo el depositario de las ideas fosilizadas. Parecía suponer una imagen geológica de la estructura social en la que las clases bajas ocupaban los estratos no sólo inferiores, sino "profundos" ${ }^{15}$, donde costumbres y tradiciones se hacían fósiles, se convertían en huellas del tiempo pasado. El "pueblo" resultaba ser un ambiguo y controvertido concepto que englobaba, por un lado, al conjunto de la sociedad, pero, por otro, específicamente aludía a los campesinos, a las clases y grupos sociales no integradas a la sociedad industrial, a las gentes iletradas que no se habían incorporado a la Modernidad. Este es el "pueblo" que conserva las costumbres, guarda "vestigios" de etapas evolutivas pasadas en forma de ritos, leyendas, adivinanzas, trajes y adornos corporales, juegos, nombres, etc. Se entiende que no es que lo haya hecho intencionadamente, sino que parece haber cumplido su tarea en la evolución sin saberlo, simplemente por defecto, es decir, por no haber recibido educación literaria, "cultura".

Ciertamente, la teoría de la evolución recupera el saber popular como conocimiento, como Cultura, aunque lo haga bajo la óptica de «supervivencia" y vincula a los diversos sectores de una sociedad que empieza a descubrirse heterogénea y diversa. Desde la teoría de la evolución todos aparecen formando parte de una misma historia, sólo que representan diferentes etapas de ella ${ }^{16}$. Pero por hacerlo con el carácter de "supervivencias", la teoría de la evolución proporcionaba una justificación a la disociación cultural entre modernos y antiguos, entre élites y pueblo, y, sobre todo, una justificación a la primacía de unos sobre otros, pues se pensaba que la evolución actuaba ortodireccionalmente. La recuperación del saber popular era, pues, a lo más una concesión a la nostalgia, pero nunca podía llegar a ser efectiva.

Desde la teoría de la evolución se entienden mejor posiciones metodológicas que condicionaron el Folklore como discurso: en primer lugar, la estrategia de urgencia que aquellos miembros de las Sociedades de Folklore adoptaron. Aún se sigue invocando esta estrategia con justificaciones similares a las de entonces. Es la consciencia de una deseable, y por otro lado inevitable, evolución lo que lleva como dedicación urgente a recopilar, registrar y acumular cuantos materiales del saber popular sean posibles antes de que desaparezcan por completo, con el supuesto de que aún están vigentes en el pueblo y pudieran perderse para siempre. El registro escrito entonces y luego también sonoro y cinematográfico o videográfico, se creía, impediría su pérdida definitiva y, por otro lado, posibilitaría su

15 Una de las formulaciones metafóricas que hizo fortuna es la de "la España profunda", muchas veces empleada para referirse a formas folklóricas.

16 La Historia de la Antropología contempla hoy al Evolucionismo cultural de Tylor, Morgan, Frazer, etc., como un esfuerzo integrador. En particular, G. W. STOCKING, Race, culture and evolution. Essays in the bistory of antbropology, Chicago, 1982; reimp. Univ. of Chicago Press. 
recuperación. La modesta estrategia metodológica que adoptó el Folklore no sólo correspondía a una disciplina auxiliar de la Antropología, como reconocía Machado, sino a un supuesto teórico, en buena medida vivenciado, la evolución de las sociedades.

La teoría de la evolución trajo consigo otra consecuencia: una cierta sensibilización hacia lo "primitivo". Se trata de una sensibilización que también afectó a la Antropología en general. Cobraron así importancia aquellos materiales especialmente reveladores de etapas anteriores de la evolución de las culturas tanto por sus rasgos formales como por su contenido. Y suponían, claro está, un constante contraste con las formas culturales actuales. Un contraste y una distancia que, sin embargo, no parecía poder ser apreciada por los propios actores, por el pueblo, sino por los recopiladores, pertenecientes siempre a la sociedad moderna.

A pesar de la exigencia de situar los materiales del Folklore en las distintas etapas evolutivas que la Antropología de Morgan y de Tylor habían marcado, nunca se produjo realmente tal clasificación. Los materiales continuaron siendo presentados como una recopilación. En buena medida el tiempo parecía haberlos afectado a todos por igual y todos parecían corresponder a un indeterminado tiempo pasado, a una especie de tiempo mítico. Si el Folklore nació con voluntad de reconstruir la historia, la presentación de sus materiales, sin embargo, olvidó que toda historia es un proceso en el que cambios y continuidades, innovaciones y pervivencias se intercalan y se entremezclan indefinidamente. Los folkloristas sólo se hicieron susceptibles a innovaciones aportadas desde la modernidad, pero no a innovaciones surgidas en otros períodos pasados ${ }^{17}$.

La pasión - porque así hay que llamarla en el caso de Machado y otros pioneros-- por el Folklore no era un mero residuo, una simple nostalgia del Movimiento Romántico. Llevaba una poderosa motivación patriótica. La formación de las Sociedades de Folklore se justificaba aludiendo al casi sagrado concepto de "nación". La historia que se pensaba reconstruir con los materiales aportados por el Folklore no era la "historia y la cultura" en general, sino "la historia y la cultura españolas". Cuando Machado, tras haber constituido en Sevilla la Sociedad de Folklore Andaluz, se traslada a Madrid y promueve la constitución de la Sociedad de Folklore Español, lo hace a través de una serie de artículos publicados en los periódicos progresistas de la época. El domingo 4 de noviembre de 1883, El Globo publica

17 Otra es la visión actual del Folklore como historia oral. Una perspectiva que se está mostrando especialmente sugerente. Véase, p. ej., R. B. BotTIGHEIMER, "Fairy tales, folk narrative research and history", Social History, vol. 14, núm. 3, octubre 1989, pp. 343-357. 
un artículo suyo dirigido "a los políticos españoles", y más específicamente a "los jefes de los partidos políticos españoles", a quienes propone asumir el Folklore como la gran obra nacional capaz de aunar a todos bajo "una comunidad de ideas y fines", y lo argumenta invocando los elementos que constituyen una nación "según el célebre historiador Herculano". (Se refiere al poeta Alexandre Herculano, perteneciente al Romanticismo portugués, autor de una Historia de Portugal.) Hay constancia de que los jefes de los partidos políticos de la época no prestaron excesiva atención a la propuesta de Machado. Aunque hay razones para suponer que, sin embargo, el Folklore no ha estado del todo desligado de la política.

Sobre el carácter patriótico de la empresa es aleccionadora la discusión que Machado y Sbarbi tuvieron acerca del uso del término "Folklore". Este había propuesto como alternativa la Academia Demológica Nacional. $\mathrm{Y}$ sus argumentos para rechazar la palabra Folklore eran los siguientes:

1. La composición de la palabra Folk-lore va en dirección inversa a la que es propia del "genio español", que diría más bien "saber popular".

2. Además, usa la letra "k", que es ajena al español, y suprime la letra «e" final en la pronunciación.

3. Es aberrante suponer que el estudio de las tradiciones esencialmente genuinas del pueblo español haya de ser bautizado con un nombre genuino de un pueblo extranjero ${ }^{18}$.

Independientemente de lo pintorescas que puedan parecer, estas razones son, a mi juicio, reveladoras de dos supuestos: uno, el incuestionable sentimiento de nación, prototipificado en el concepto de "pueblo", que suscitaba el Folklore; y dos, la potencialidad de particularización, de singularidad que conllevaba. La pretensión de obra nacional unificadora que tenía Machado era ingenua, pues el Folklore, como enseguida se puso en evidencia, podía alentar las demandas de reconocimiento de singularidad de pueblos y buscar en él legitimidad para reclamar su carácter de nación.

Habían sido los hermanos Schlegel quienes a comienzos del XIX subrayaron que la grandeza de una nación se medía por el grado de adhesión a su lengua, religión, usos, costumbres, pensamiento y vida. Una idea anticipada por Herder, sólo que en los Schlegel se convierte en un ideario político y cultural. Eran las tradiciones populares lo que daba convergencia y coherencia a una nación, la creaban. La fuerza de las tradiciones contribuía a la autoconciencia, a la conciencia del pasado como realidad histórica ${ }^{19}$.

18 J. M. SBARBI enunció su fobia hacia la palabra folk-lore en su Monografía sobre los refranes, adagios y proverbios castellanos, Madrid, Imp. y Lit. de los Huérfanos, 1891, p. 182. Reproducida por A. GuichoT, o. c., p. 180.

19 Sobre la influencia de los Schlegel y Herder en la génesis del Volkskunde alemán, véanse R. Corso, El Folklore, Buenos Aires, Eudeba, 1966, y G. CocchiarA, Storia del Folklore en Europa, Turín, Einaudi, 1952. Sobre el nacionalismo, el concepto de "pueblo" y el uso 
Y así, primero Von Arnin y Brentano y luego los Grimm, comenzaron la labor de recopilación de cuentos, mitos, canciones, etc. ${ }^{20}$. Y no es que estuvieran propiamente interesados en los cuentos, mitos, canciones, etc., de los pueblos en general, sino de su propio pueblo, del pueblo alemán. La extensión del Volkskunde, o si quiere del Folklore, a otras naciones no es signo de universalización, sino una reacción mimética de reafirmación frente a otros. La paradoja, por tanto, quedó inscrita en el mismo seno del Folklore. Como Ciencia debía buscar un objetivo universalizador, pero como obra nacional revitalizaba el particularismo, la singularidad.

El concepto esencial que incorporaba el Volkskunde era el Volk, el "pueblo". Un sujeto colectivo, casi un organismo, transhistórico, que englobaba a todos, cualquiera que fuera su clase o condición social y a quien se atribuía todo tipo de manifestación cultural, pero que se manifestaba especialmente en obras colectivas, anónimas. A este sujeto colectivo, el "pueblo", se le caracterizaba con personalidad propia. Tal vez el término que empleaba Sbarbi, "genio", sea el más adecuado para transcribir una entidad biopsicológica. Era una entidad formada por herencia y por tradición, ligada a un país. Una entidad a la que se le atribuían sentimientos, pasiones, habilidades, intereses y ambiciones. $Y$ sus manifestaciones más genuinas, más auténticas, había que buscarlas entre aquellas que habían pervivido a lo largo del tiempo, entre aquellas que lo mostraban en su etapa originaria, en el tiempo mítico de su gestación como pueblo.

La obra de los hermanos Grimm, y en concreto sus Cuentos infantiles y del hogar, inicia la larga serie de recopilación de manifestaciones de ese "pueblo" que luego fue continuada en todos los países europeos y después en las diferentes naciones americanas. Esa obra no sólo dirigió la atención preferente hacia los materiales literarios del "saber popular", sino que orientó a los investigadores hacia determinados sectores sociales, entre quienes el genio popular afloraba con mayor intensidad, con mayor autenticidad: la esencia del pueblo se encontraba en el mundo campesino.

En la segunda edición de esa obra, que, como es sabido, alcanzó un éxito sin precedentes, los hermanos Grimm introdujeron un importante giro en la comprensión de tales materiales. Los cuentos de hadas ya no eran sólo maravillosos estéticamente hablando, sino que debían ser considerados como importantes documentos históricos. Eso implicaba una peculiar visión de la historia, que para ellos dejó de ser una mera secuencia de hechos cronológicos, sino que debía ser construida a partir de lo que el

de una supuesta cultura popular, véase E. Gellner, Naciones y nacionalismo, Madrid, Alianza, 1988, especialmente pp. 77-83.

20 Ludwig Joachim VON ARNIM y C. BRENTANO publicaron, entre 1806-1808, Das Knaben Wunderborn, en Heidelberg, tenida como una de las primeras colecciones de cantos populares alemanes. Esta obra y los Kinder- und Haus-Märchen de los hermanos J. y W. GRIMM, Leipzig, 1812 (la segunda edición en 1819 y 1822), no son estrictamente las pioneras, pero se reconocen como las iniciadoras del coleccionismo de Folklore. 
pueblo pensaba, soñaba. Los cuentos de hadas hablaban de una edad dorada, en la que la naturaleza vive, los animales hablan, las estrellas están al alcance de los hombres. Un mundo encantado que revelaba lo más profundo del espíritu de un país. En el mundo mágico de los cuentos, los hermanos Grimm descubrieron creencias de los antepasados, pensamientos olvidados y perdidos, una religión, un paganismo que luego acabó fundido, confundido con el cristianismo. Los cuentos pasaron a tener valor folklórico, es decir, etnográfico.

El "pueblo", los pueblos, que desde los hermanos Grimm han ido siendo mostrados a través de cuentos, mitos, leyendas, refranes, canciones, danzas, fiestas, etc., aparecían idealizados. Parecían haberse contagiado del maravilloso ambiente de los cuentos de hadas. Los narradores, las personas reales que contaban estos cuentos o cantaban tales canciones, apenas eran mentados. Parecían haber sacrificado su individualidad en favor del alto concepto de aquello a quien representaban: el "pueblo". Las situaciones en las que tales cosas se contaban quedaron en esquema descritas como una transmisión de padres a hijos, de abuelos a nietos, en una comunicación directa, segregada de cualquier perturbación cotidiana. Ese ambiente de hogar, al amor de la lumbre, que se presentaba como prototipo de la tradición oral, dejaba adivinar que, a pesar de que fuera hubiera una horrible tempestad de nieve y frío, nada podía alterar ese trascendental acto de transmisión de saber y, sobre todo, nada podía alterar el mensaje mismo, el texto. Esa imagen es un ejemplar modelo - por otra parte un viejo modelo- de presentación de los materiales folklóricos. Sólo importaban los textos. El contexto, la situación, los que en ella intervenían, los ambientes en los que se movían, las relaciones entre las personas, los trabajos, las condiciones en las que trabajaban, sus dificultades para salir adelante en la vida, todo lo que formaba parte de su vida real, inmediata, todo eso quedaba fuera. El acceso a la verdadera historia, la historia profunda, se hacía a costa de desdeñar la realidad presente, la historia inmediata. El Folklore, en su afán por mostrar al "pueblo", ha privilegiado sus manifestaciones y desdeñado la realidad social. Es el idealizado concepto de "pueblo" que asumían los folkloristas lo que les llevó a presentar los materiales del Folklore descontextualizados.

Otra de las paradojas del Folklore es que a pesar de haber iniciado ese método que hoy conocemos como el trabajo de campo, la obtención de los datos sobre el terreno, la búsqueda de los informantes, el registro escrupuloso de lo que ellos comunicaban al investigador ${ }^{21}$, sin embargo, tanto concentraron sus esfuerzos en el puro texto que retornaban a sus gabinetes sin apenas haber captado la compleja realidad de la vida de los campesi-

21 En realidad, el trabajo de campo de los folkloristas no es precisamente el mismo trabajo de campo que caracteriza la labor de los antropólogos, pero sí dio lugar a las encuestas lexicológicas, estrechamente relacionadas con ciertas formas de hacer Etnografía. 
nos y las clases populares. Su alto concepto de "pueblo" les impidió acceder al pueblo real.

Lo que los hermanos Grimm hicieron fue fundamentalmente colecciones. Lo mismo que los entusiastas seguidores sevillanos del Folklore continuaron haciendo bastantes años despues. $\mathrm{Y}$ lo mismo que innumerables folkloristas han seguido haciendo a lo largo de los años. Machado, con modestia, reconocía que eso era lo que correspondía hacer a una ciencia auxiliar. Otros luego han justificado esa tarea, evitando intencionadamente cualquier elaboración teórica como una consecuencia obligada de un objetivo estrictamente etnográfico. Sea como fuere, esta actitud metodológica ha llegado a dar impronta al discurso folklórico. Tal discurso parece consistir en una sucesión ininterrumpida de textos o en una exposición continua de materiales relativamente ordenados cuya unidad es externa al propio discurso. Son atribuidos a un mismo sujeto colectivo, anónimo, y generalmente clasificados dentro de un mismo género. Leídos los textos uno detrás de otro, el discurso se hace ininteligible, porque cada texto es un discurso cerrado y el siguiente no supone para nada el anterior, a pesar de que gráficamente esté situado a continuación. Una colección de Folklore es un continuo discurso interrumpido. Esta impresión es especialmente cruda, hasta convertirse en discurso obsesivo, cuando uno lee colecciones de refranes, de adivinanzas, de cantares $^{22}$.

A pesar de todo, me propongo ahora mostrar la lógica de ese discurso, que, a mi entender, no está precisamente carente de supuestos teóricos.

La mayoría de los libros de Folklore dicen ser tres cosas: 1) una colección, 2) de textos, 3) atribuido a un sujeto colectivo, referido a veces como nación, a veces simplemente como lengua, pero explícita o implícitamente caracterizado como "pueblo" diferentemente circunscrito a una localidad, una comarca, una provincia, una región, un Estado o una nación $\sin$ Estado.

No voy a entrar estrictamente en la técnica de registro de los datos, sino en la presentación de éstos en forma de colecciones. Lejos de ser un simple resultado de técnicas de registro de datos, las colecciones parecen seguir un código cuyas bases son las siguientes:

1. En primer lugar, un texto incluido en una colección aparece como único. Aun cuando el mismo texto se haya obtenido de varios informantes, no parece tener sentido reproducirlo tantas veces cuantas haya aparecido en el trabajo de campo. En la colección aparece una sola vez. Y es

22 La bibliografía de colecciones de Folklore es inmensa. Como muestra, baste aludir a A. Machado, Colección de enigmas y adivinanzas en forma de diccionario, Sevilla, 1880; F. Rodríguez Marín, Cantos populares españoles, Sevilla, 1883; A. M. EsPinosa, Cuentos populares españoles, Madrid, CSIC, 1946-47; L. MARTÍNEZ KLEISER, Refranero general ideológico español, Madrid, Real Academia, 1953; V. GarCía DE DIEGo, Antología de leyendas, Barcelona, Ed. Labor, 1958, etc. 
tratado como una unidad singular y, en ocasiones, como una unidad-tipo. Pueden, sin embargo, exponerse variantes, si bien las modificaciones que éstas presentan se consideran menores y remiten al texto tipo.

2. Un texto ha de ser completo. Se les supone a todos una forma acabada y, por tanto, se desdeñan fragmentos o versiones incompletas.

Estas dos reglas de toda colección toman como supuesto que los textos procedentes de un informante pueden ser acumulados junto con los procedentes de cualquier otro, pues todo informante es, en esencia, representante de un coletivo. El mejor informante, el especialmente dotado, es aquel que mejor representa al colectivo. Como si un informante no fuera más que una obligada vía de acceso al sujeto colectivo a quien verdaderamente se atribuyen los textos.

Además, estas dos reglas implican ciertas asunciones teóricas acerca de la evolución de los textos. A saber:

- Que las formas-tipo completas son propias de informantes especialmente dotados o de lugares específicos y genuinos, de modo que las versiones o formas incompletas se consideran características de estadios anteriores o posteriores y en todo caso imperfectas.

- Las versiones incompletas pueden atribuirse a déficit de memoria (pues la memoria colectiva no tiene otro modo de materializarse que por medio de las limitadas memorias de informantes individuales), pero a veces podrían ser un signo de la extrema antigüedad de un texto.

Es el compilador quien decide qué texto es texto-tipo y completo. $\mathrm{Y}$, llevados por su afán, algunos hay que toman diversos fragmentos, los combinan y reconstruyen un texto acabado y perfecto.

3. Todo texto ha de ser específico. Es decir, adecuadamente encuadrado en el género elegido como objeto de recopilación. Una colección presenta textos clasificados por géneros. Lo que supone una concepción nítida de qué sea un género, que suele ser ilustrada por una forma paradigmática, llamada, en la escuela clásica del Folklore, "forma pura". Se reconocen, efectivamente, formas híbridas, con características de dos o más géneros.

Al seguir esta regla, el discurso folklórico induce la idea de que los textos de la tradición oral forman conjuntos homogéneos. En realidad, los homogeiniza el propio discurso, del mismo modo que al presentar juntos textos obtenidos de diversos informantes no sólo los reúne, los unifica. Unificar y homogeneizar no son más que acciones normalizadoras.

4. Toda colección tiende a ser exhaustiva. Es cierto que muchas colecciones se contentan con muestras, pero la exhaustividad indica un 
objetivo cumplido de conocimiento e investigación. Los investigadores parecen tener como norma el aportar nuevos materiales, no registrados en previas colecciones. Con ello creen dotar de mayor valor a su discurso. $\mathrm{Y}$ a veces entran en competencia al comparar no sólo el tamaño, sino la completitud de su obra. Sin embargo, este objetivo de exhaustividad está aludiendo, ya sea de forma explícita o no, a la enorme potencialidad creativa que se le supone a ese sujeto colectivo al que atribuye los textos.

5. Y, por otra parte, el valor de un texto en una colección (y de la colección misma, por tanto) aumenta si se trata no sólo de un texto no conocido, es decir, no convertido hasta entonces es discurso folklórico, sino de un texto singular, ya sea por su belleza estética, por su fuerza expresiva, por su exotismo, etc. Tales textos singulares pueden convertirse en referentes privilegiados del sujeto colectivo, ensombreciendo al resto.

6. La normalización de los textos que realiza el discurso folklórico se refuerza con otros dos aspectos más, debidos a normas que rigen la escritura y la publicación impresa de estos materiales. Pese a la tendencia a la exhaustividad, muchas colecciones son selectivas. Si todo es posible objeto de recopilación, no todo se considera publicable. Los recopiladores parecen creer que algunos textos son tolerables si son oídos, pero no si son leídos. Algunas veces, el discurso folklórico parece un ejercicio de moralidad y camufla o simplemente elimina lo que podría considerarse soez, desvergonzado o impúdico.

$Y$ es que el compilador se comporta como mediador y su discurso como mediación entre los informantes y los lectores. Dando por sentado, además, que unos y otros son diferentes y no comparten las mismas normas y valores. Es como si el discurso folklórico no se concibiera destinado a aquellos que proporcionaron los materiales para elaborarle.

7. Y, naturalmente, las colecciones ortografían. Es decir, los textos de la tradición oral se escriben según la ortografía académica o bien siguiendo ciertas convenciones pseudofonéticas. Pues es evidente que una estricta representación fonética las haría ilegibles para la mayoría de los lectores. Pero tales convenciones han de permitir reconocer o identificar al sujeto colectivo al que se atribuyen los textos. Esto es un modo de crear una imagen "gráfica" de él.

8. Algunas colecciones numeran los textos, lo que ya supone un asombroso tratamiento para un texto de la tradición oral, pero lo que no deja de hacer una colección es otorgar un orden a los textos. Hay dos hábitos en los recopiladores a la hora de otorgar un orden a los textos: uno, tomar la primera letra y situarlos según un orden alfabético, de la A a la Z; y dos, distribuirlos en conjuntos temáticos o conceptuales. 
Muchos, ante el cúmulo de problemas que presenta una distribución temática y por intentar ser consecuentes con su postura de asepsia etnográfica que trata de evitar toda interpretación, prefieren el alfabético. Y en realidad lo que tratan de reproducir es un diccionario. Incluso añaden una breve glosa a textos breves como refranes, frases proverbiales y adivinanzas. Glosa, por otro lado, necesaria para poder lograr la comprensión de muchos textos. De modo que el modelo de codificación "diccionario" acaba siendo aún más fielmente seguido.

El discurso folklórico se nos revela como un método para proveer de nueva contextualización que los convierta en material consultable a textos que, cuando fueron obtenidos de los informantes, se les privó de los contextos en los que efectivamente eran mensajes significativos. Con ello el discurso folklórico acaba invistiéndoles de una nueva significación, esta vez determinada por la relación de comunicación entre los recopiladores y los lectores.

No debe olvidarse tampoco que el objetivo de escriturar los textos de la tradición oral suele ser invocado por parte de los recopiladores como tratamiento necesario para lograr su conservación, para conseguir una especie de perdurabilidad eterna, pues aunque la tradición se quebrara - y con más razón si se ha quebrado ya- las generaciones venideras pueden conocerlos.

9. Finalmente, la regla más básica que sigue toda colección de textos es que éstos han de ser auténticos. Los matices y relieves de la autenticidad son múltiples, pero en esencia se configuran en torno a dos cualificaciones: que sean de tradición oral - digamos no literaria, para simplificar- y que sean pertenecientes a un sujeto colectivo determinado, es decir, a un "pueblo", cualquiera que sea su delimitación sociopolítica (incluyendo el hecho de que estén formulados en una determinada lengua). Ambas van relacionadas. Todo discurso folklórico tiene una referencia lingǘstico-social. No existe el discurso folklórico como tal, sino el Folklore mexicano, el Folklore alemán, el Folklore gallego, el Folklore español, o el Folklore del Valle del Tiétar, etc. Y se supone que ese sujeto colectivo, ya sea comunidad local, región, patria o nación y en último término "pueblo", es creador y transmisor de un saber que enuncia fundamentalmente de modo oral.

El criterio de oralidad obliga a tomar como espúrea toda forma literaria, y el de referencia al "pueblo", soportado por una escrupulosa identificación de origen de los informantes, obliga a rechazar textos aportados por quienes se consideran extraños. Pero descubre que el más autentico "pueblo" no ha tenido contacto con lo literario, sino que expresa claramente que lo ha recibido de sus mayores. Es así como la tradición se convierte en verdadero proceso forjador de autenticidad. En cierto modo 
es un inevitable reconocimiento de analfabetismo -circunstancia que a modo de prueba irrefutable de autenticidad se hace constar en algunas colecciones-, pero no de ignorancia, precisamente no de eso, pues la propia colección es muestra del saber del pueblo. Y la abundancia e ingeniosidad, la sensatez, prudencia o agudeza de los textos se subrayan como características de ese saber. Todavía más, los recopiladores llegan a hablar en ocasiones del "aroma" que exhalan los textos auténticamente populares. Rasgos formales de arcaísmo, espontaneidad, falta de artificio y otros son algunos de los modos de racionalizar ese por otra parte inexpresable "aroma".

Pero, además, la identificación de los informantes es en realidad gené. rica. En las colecciones, los informantes están indiferenciados, son anónimos. El anonimato no es un criterio de autenticidad, es propiamente resultado del desdibujamiento de informantes que realiza toda colección. Centradas en los textos, las colecciones borran cuantos rasgos contribuyan a diferenciar individualmente a los informantes, desdeñan variantes, modificaciones, manipulaciones, toman textos únicos, y los acumulan en secuencia ininterrumpida, haciendo de lo que en realidad son, múltiples discursos de numerosos, distintos locutores, enunciados en múltiples y diferentes contextos, un único y homogéneo discurso, el discurso folklórico, para el que configuran un nuevo contexto. El discurso folklórico transforma a quienes son locutores de mensajes, ante una audiencia que comparte con ellos códigos particulares de comprensión, en informantes tradicionales. El concepto de "tradición" no tiene el mismo significado cuando es invocado por un campesino para dar autoridad al refrán con el que ironiza sobre la conducta de su vecino o al cuento con el que trata de entretener a sus nietos, que cuando es exigido por parte del investigador para garantizar la autenticidad del texto que ha recogido ${ }^{23}$. De esa manera el sujeto colectivo al que atribuyen tantos y tan singulares textos es, al fin y al cabo, un constructo, un resultado del propio discurso folklórico.

Y también de la misma manera se dota a ese sujeto colectivo de características de personalidad, tales como ingenio, sorna, lirismo, sensibilidad o rudeza, pragmatismo, envidia, individualismo, etc., que acaban convirtiéndose en argumentos para componer eso que se ha llamado el carácter nacional y que en realidad oculta un manojo de estereotipos que se explotan a conveniencia ${ }^{24}$.

Ese sujeto colectivo es en realidad la hipóstasis del locutor tradicional, pues los textos proceden de muy diversos informantes y los utilizan con muy distintos intereses. Y como constructo, como hipóstasis, es aún mayor

23 No son tan numerosos como pudiera creerse los análisis de la "tradición"; p. ej., J. Caro Baroja, "Estructura y tradición. Vocablos usuales en las ciencias antropológicas", Revista de Dialectologia y Tradiciones Populares, 1974, pp. 3-32.

24 J. Caro Baroja, El mito del carácter nacional. Meditaciones a contrapelo, Madrid, Seminarios y Ediciones, 1970. 
cuanto más genérico, más abstracto e idealizado sea ese "pueblo" al que se le atribuyen. Los textos, en tanto que mensajes reales, significativos, no son sumables. No hay locutor, ni siquiera comunidad real de locutores y audiencia, que usen y conozcan tantos refranes, dichos, cantos, cuentos, leyendas, adivinanzas o mitos como traen las colecciones ${ }^{25}$. Sólo las colecciones crean esa ficción.

El discurso folklórico manipula dos procesos, el creativo, el de la invención de textos, y el reproductivo, el de su transmisión. El modo de hacerlo recuerda al viejo mecanismo de la alienación. Atribuye a un ente ficticio, la región, la nación, el pueblo, la capacidad de crear tanta variedad, tanta poesía, tanta palabra ingeniosa, tanto dicho sabio, tanto imaginativo cuento, etc., y le atribuye la capacidad de perpetuarlo. La colección hace que ambas funciones, creación y perpetuación, invención y transmisión, al anonimizar, homogeneizar y unificar los textos, sólo puedan ser atribuidas a un sujeto colectivo. Ese sujeto colectivo puede ser el conjunto de todos, pero no es un único y distinto todo.

Lejos, pues, de estar carentes de postulados teóricos, el discurso folklórico, y su expresión más aparentemente exenta de interpretaciones que son las colecciones, los llevan inscritos en su mismo método, en su aparentemente aséptico modo de hacer etnografía ${ }^{26}$.

\section{III}

Desgraciadamente, el influyente artículo que W. Bascom publicó en 1954 titulado "Cuatro funciones del Folklore" 27 no parece haber sido conocido por la mayoría de los folkloristas españoles. Es curioso hacer notar que el artículo trataba de llamar la atención de los antropólogos americanos hacia el Folklore - es decir, hacia los textos de la tradición oral- y de mostrar las relaciones del Folklore con la Cultura. Tomaba Bascom, como datos ilustrativos, materiales extraídos de su trabajo de

25 Según la ficción a la que induce una colección, el hablante ideal español podría conocer los 65.083 refranes de la colección de Martínez Kleiser, los 8.174 cantos de la colección de Rodríguez Marín, las 1.061 adivinanzas de la colección de Machado, los 279 cuentos de la colección de Espinosa, etc.

${ }^{26}$ No debiera concluirse de este análisis la irrelevancia o inutilidad de las colecciones de materiales de Folklore. Al contrario, colecciones realizadas en distintos lugares y en distintos tiempos, si respondieran realmente al uso de estos materiales, serían extremadamente valiosas para mostrar la evolución y el contraste entre las formas expresivas de los grupos sociales de distintos tiempos y distintas culturas. $Y$ si fueran presentadas de una forma contextualizada, distinguiendo en lo posible situaciones, locutores y audiencia y significados variables, incrementarían enormemente su valor. En todo caso, y según decían los clásicos, como "Tesoro" de la lengua son indispensables.

27 W. BASCOM, "Four Functions of Folklore", Joumal of American Folklore, vol. 67 (1954), pp. 333-349. 
campo en culturas africanas. Las funciones que él desglosaba en su trabajo eran las siguientes. En primer lugar, una función expresiva, es decir, un privilegiado conjunto de formas culturales a través de las cuales se muestran significativos aspectos de las sociedades. En segundo lugar, una función de justificación, de validación de conductas e instituciones sociales. En tercer lugar, una función pedagógica, pues con él se trata de inculcar actitudes y principios generales y a la vez se transmiten valiosas informaciones que pudieran ser útiles en las vicisitudes de la vida cotidiana. $Y$, en cuarto lugar, el Folklore contribuye al ejercicio de la presión y el control social, fomentando conformidad a las pautas aceptadas de conducta.

Quisiera que esta breve síntesis del trabajo de Bascom sirviera de guía para ilustrar las funciones del Folklore, pero llamando ahora Folklore no a los contenidos, sino a la ciencia, estudio, interés o afición por lo que ha venido finalmente a llamarse "cultura popular". Trato de sugerir que estas funciones del Folklore corresponden con asombrosa exactitud a los diversos modos de manipulación político-social que se han hecho de él.

En primer lugar, el Folklore ha sido presentado como muestrario de la singularidad, expresión viva de los valores de un pueblo. A través de él se ha construido una imagen de un pueblo unas veces ingenua, otras exótica, otras vibrante; unas veces marcando la distintividad, la diferencia irreconciliable, otras la variedad dentro de la unidad de la patria. La imagen del pueblo que ha configurado el Folklore se ha ido acomodando a los diversos planteamientos político-sociales de la historia de la España del último siglo. El Folklore ha servido para denigrar particularismos y para exaltar una unidad de destino. Ha servido para proporcionar signos de identidad a pueblos sojuzgados y para forjar una identidad a pueblos en el fondo no tan diferentes.

El Folklore como ciencia ha contribuido a ello, tal y como he tratado de mostrar anteriormente, pero tiene el Folklore un carácter más que no puede ser desagregado aquí. Ha sido también normalizado como Arte. El interés por el Folklore corresponde no sólo a folkloristas, sino también a folklóricos (y a folklóricas, claro está). El desarrollo del Folklore como espectáculo ha dado una extremada importancia a la función expresiva del Folklore. El Folklore se ha introducido en la Modernidad a través de la cultura del ocio y convertido en nuevo ritual, recreando en un escenario un nuevo y normalizado contexto; ha servido, como suelen decir las folklóricas, "para pasear la imagen de España", "para españolear". No sólo de España, también por lo mismo de Galicia, Euskadi, Castilla, etc. Lo expresivo está en lo de "la imagen de...". Un espectáculo folklórico es una forma del discurso folklórico que, como se habrá notado, sigue un código cuyas normas son muy similares a las que antes he desglosado a propósito de las colecciones. En general, son colecciones escenografiadas, ya sean de cantares, de melodías o de danzas. Cada acto es único, no tendría sentido que se 
repitiera con sus variantes, es singular, integrado en un género. El espectáculo tiende a ser variado, es decir, persigue una exhaustividad cualitativa o muestral, y sin embargo es selectivo, etc. Y, sobre todo, sus intérpretes tratan de imprimir a lo que hacen un sello de autenticidad, si bien, como los recopiladores, son propiamente mediadores entre sus informantes y el público al que destinan sus actuaciones. Hay, no obstante, una diferencia esencial entre un espectáculo y una colección, y es que aquél es un ritual e incorpora los recursos de los rituales. Entre ellos, la posibilidad de producir una identificación entre el intérprete y su público. Un espectáculo, más comprensiblemente que una colección impresa, puede llegar a producir una efervescencia en torno a una determinada noción de "pueblo" y puede llegar a convertirse en un acto de afirmación nacionalista.

La segunda función del Folklore como Ciencia o como Arte ha sido la de justificación y validación de conductas e instituciones sociales. Aquí es necesario invocar una vez más el ambiguo, o al menos multívoco, concepto de "tradición". La función expresiva del Folklore le hace parecer demasiado inocente. Apropiado, sin embargo, por grupos sociales de élite intelectual o por instituciones políticas, el Folklore se convierte en instrumento de validación de conductas o instituciones que se presentan como "populares». En su nombre se justifica el mantenimiento de "tradiciones" como, por ejemplo, un recorrido procesional o la recuperación de fiestas populares, aunque de hecho se esté produciendo al mismo tiempo la supresión o desaparición de otras. Curiosamente, la "tradición" ha sido tanto una caracterización que permite postular y hacer deseables transformaciones sociales - por ejemplo, el discurso sobre modos productivos ha combatido usos "tradicionales" como las matanzas o procesos de trabajo escasamente rentables-, como un argumento que anima a recuperaciones y revitalizaciones. Pero especialmente el Folklore ha sido empleado como ideología publicitaria. En el campo de la artesanía, concretamente, el discurso folklórico, y también las muestras, exposiciones y ferias, han contribuido a dar imagen y a validar como "artesanos" productos cuyo mercado está controlado por mayoristas e intermediarios, y que o bien son elaborados casiindustrialmente en sus talleres con un toque artesanal en el acabado, 0 bien son fabricados por pequeños artesanos autónomos que en realidad se convierten en subempleados de esos mayoristas e intermediarios, que son quienes evidentemente reciben la mayor parte de los beneficios de ventas, precisamente animadas por descripciones y muestras basadas en los otros, en los auténticamente artesanos. La artesanía es un buen ejemplo de cómo se produce la apropiación del Folklore por grupos o sectores sociales que no son en último término los beneficiarios principales de los valores que se le atribuyen ${ }^{28}$. Pero no sólo es la artesanía. El Folklore como espectácu-

${ }^{28}$ La cuestión de quiénes son los receptores principales de los beneficios que genera el Folklore, convertido en bien cultural dentro del mercado del ocio y espectáculos, no ha sido nunca suficientemente planteada. ¿A quién corresponden -o cómo distribuir - los 
lo está en gran medida del mismo modo apropiado por quienes no son sino mediadores e igualmente justificado por recopilaciones, descripciones y certámenes basados en los auténticos protagonistas que, sin embargo, no son los principales beneficiarios.

La tercera función del Folklore como Ciencia y como Arte, la pedagógica, fue ya planteada desde los inicios del Folklore en España. Muchas colecciones de cuentos, adivinanzas, leyendas, etc., fueron destinadas a los niños, y en todo caso al pueblo en general, para que "llegaran a conocer mejor y apredieran a amar" al pueblo al que pertenecían. Luego, la obra de la Sección Femenina del Frente de Juventudes tomó esta función pedagógica como objetivo de existencia. Cito el segundo párrafo del Preámbulo de un grueso Cancionero editado por ella en 1943: "Tened en cuenta que el principal objetivo de este libro no es otro que el de iniciar a nuestras Flechas en el alto interés artístico que ofrece la música popular española, para despertar en su espíritu la inquietud, el ansia de ampliar sus conocimientos de este bello arte e irles dando a conocer las populares bellezas musicales, y así, de un modo alegre y sencillo, ir cultivando y despertando en las almas jóvenes un amor profundo por España, para que, a través de las canciones típicas, natural vibración espiritual de los pueblos, la conozcan más amplia e íntimamente, y de esta forma conseguir la perfecta unión de nuestra Patria, logrando que las próximas generaciones, compenetradas en un mismo sentimiento espiritual, hagan una realidad "la unidad entre los hombres y las tierras de España" " 29 .

No debe ser sorprendente que en cierto modo el discurso folklórico se haya dirigido hacia maestros y educadores. Martínez Torner, Arcadio Larrea y otros folkloristas escribieron en los años cincuenta sendos libros titulados El Folklore y la escuela ${ }^{30}$ con la esperanza de que sus ideas fueran acogidas por los responsables políticos de las instituciones escolares y con el supuesto de que el mejor modo de contribuir al mantenimiento de una "tradición" era activarla, es decir, transmitir el Folklore como educación a las generaciones jóvenes. Naturalmente, el Folklore propuesto para ser transmitido en las escuelas era un Folklore normalizado, seleccionando aquellos materiales que se suponían más apropiados para los niños, según exigía la pedagogía y la moralidad de la época.

Es difícil evaluar la efectividad de esta tercera función del Folklore. Pero sí es cierto que algunas tradiciones, por ejemplo festivas, desaparecidas o en trance de desaparición porque los adultos de los pueblos habían

derechos de autor de una canción popular anónima? ¿A quién los de un libro de cuentos tradicionales? ¿Quién tiene la patente de una pieza de cerámica tradicional? ¿Qué beneficio corresponde a los informantes que han enseñado a un coreógrafo una antigua danza?, etc.

29 Cancionero de la Sección Femenina del Frente de Juventudes de FET y de las JONS, Madrid, Departamento de Publicaciones, 1943.

30 E. Martínez Torner, El Folklore en la escuela, Buenos Aires, Ed. Losada, 1965; A. LARrea, El Folklore y la escuela, Madrid, CSIC, 1966. 
empezado a encontrarlas vacías o simplemente ridículas se han continuado algún tiempo, gracias al empuje de un animoso maestro o maestra, que llegó a formar, por ejemplo, un grupo de danza para interpretar el paloteo u otras mudanzas durante la procesión el día de la fiesta. El cambio de sentido que eso puede haber supuesto obliga una vez más a asombrarse de los múltiples significados del concepto de "tradición".

Hay un aspecto que no puede dejar de destacarse en esta reducción del Folklore a asunto infantil. Entre el conjunto de proposiciones evolucionistas referidas al Folklore al que antes aludía, puede encontrarse la inquietante idea de que materiales culturales que en un tiempo más o menos remoto eran trascendentales acciones, o saberes de especialistas, o de la gente adulta de un pueblo, han devenido con el tiempo en inocentes juegos de niños. Así se dice que antiguas prácticas adivinatorias han acabado siendo cuentos como Juan Sin Miedo, etc. ${ }^{31}$. La asunción de la teoría evolucionista convirtió a los niños en inconscientes depositarios de fósiles culturales. Posiblemente, a la vez, indujo la idea de que el Folklore era una forma cultural degradada, pues sólo así podía explicarse que acabara estando en manos de niños.

Como nota Bascom, las funciones segunda y tercera del Folklore están muy relacionadas con la última: el ejercicio del control social, la inducción de conformidad a pautas aceptadas de conducta. Y, efectivamente, el Folklore como ciencia y como arte puede haber sido útil a la hora de ocultar la triste o doliente realidad social y económica de los pueblos. La imagen ideal de pueblo que transmitía, fomentada, por ejemplo, por colecciones de cuentos con soluciones maravillosas a conflictos semejantes a los reales y animada por medio de alegres canciones y bailes, puede haber servido para distraer a un pueblo que, al mismo tiempo, estaba sometido a cartillas de racionamiento y a represión política. Naturalmente que puede haber ocurrido así. No es necesario insistir más en ello. Pero hay otras formas sutiles de producir conformidad a las normas, y una es el que, una vez establecida una imagen de pueblo, las gentes que lo componen han de sujetarse a ella, so pena de decepcionar a quienes pretenden conocerles. El discurso folklórico ha sido y continúa siendo un aliado importante del turismo. El mantenimiento de las tradiciones, la autenticidad de la «vida tradicional" de sus gentes ha sido divulgado por el discurso folklórico y transferido al discurso turístico, de modo que gracias a él determinados pueblos se han convertido en centros de peregrinación con motivo de las fiestas o como centros de recepción de un turismo en época de vacaciones que hasta pretende instalarse temporalmente allí. La cuestión es compleja y merecería un estudio detenido, incluyendo la invención de tradiciones -algo, por otra parte, nada nuevo en el Folklore-. Pero aquí simplemen-

31 Consúltese especialmente el cap. III, "Las esencias del Folkloren, del Manual de Folklore de L. y N. DE HOYOS, Madrid, Revista de Occidente, 1947. 
te pretendo apuntar de qué modo el turismo se ha apropiado del Folklore hasta llegar a exigir de un pueblo no que se muestre cómo es, sino que se muestre según la imagen que de él se tiene. Zamarramala, La Alberca, Candelario, por ejemplo, y muchos otros pueblos parecen haber sido especialmente sometidos a esta última función del Folklore: la conformidad con la imagen que de ellos se tiene.

Pero más propiamente esos pueblos parecen haber captado a la perfección los rasgos más característicos del Folklore, sus paradojas. Pues gracias al turismo han sido capaces a la vez de "mantener sus tradiciones" y de progresar social y económicamente, precisamente por mantenerlas 